\title{
Narrativa
}

\section{Barbara TONZAR, Colonie letterarie. Immagini dell'Africa italiana dalla fine del sogno imperiale agli anni Sessanta}

\section{Teresa Solis}

\section{OpenEdition}

\section{Journals}

Edizione digitale

URL: https://journals.openedition.org/narrativa/580

DOI: $10.4000 /$ narrativa. 580

ISSN: 2804-1224

\section{Editore}

Presses universitaires de Paris Nanterre

\section{Edizione cartacea}

Data di pubblicazione: 1 décembre 2018

Paginazione: 187-188

ISBN: 978-2-84016-325-1

ISSN: $1166-3243$

\section{Notizia bibliografica digitale}

Teresa Solis, «Barbara TONZAR, Colonie letterarie. Immagini dell'Africa italiana dalla fine del sogno imperiale agli anni Sessanta», Narrativa [Online], 40 | 2018, online dal 01 novembre 2021, consultato il 08 décembre 2021. URL: http://journals.openedition.org/narrativa/580 ; DOI: https://doi.org/10.4000/ narrativa.580

Questo documento è stato generato automaticamente il 8 décembre 2021.

Narrativa est mise à disposition selon les termes de la Licence Creative Commons Attribution 4.0 International. 


\section{Barbara TONZAR, Colonie letterarie. Immagini dell'Africa italiana dalla fine del sogno imperiale agli anni Sessanta}

Teresa Solis

\section{NOTIZIA}

Barbara TONZAR, Colonie letterarie. Immagini dell'Africa italiana dalla fine del sogno imperiale agli anni Sessanta, Roma, Carocci, 2017, 154 p.

1 Frutto delle indagini e delle riflessioni condotte nell'ambito di un dottorato di ricerca svolto presso l'Università Palacký di Olumuc, Colonie letterarie esplora come l'Africa italiana sia stata rappresentata e raccontata in produzioni letterarie pubblicate in una precisa fase storica, quella indicata dal sottotitolo. L'arco cronologico considerato va dalla fine dell'Impero all'inizio degli anni '60, quando si conclude l'AFIS, Amministrazione Fiduciaria Italiana in Somalia, unico caso in cui il processo di decolonizzazione sia stato accompagnato dalla stessa potenza colonizzatrice. L'idea di "colonia letteraria" rinvia quindi anche a una sorta di enclave letteraria, un territorio colonizzato da un certo tipo di immaginario esotizzante, difficile da sradicare anche dopo la fine ufficiale del colonialismo. Le colonie letterarie sono quelle rappresentazioni che, malgrado il mutato clima politico, portano ancora le tracce dell'ideologia coloniale orientaleggiante e razzista che ha caratterizzato, giustificato e alimentato l'espansione italiana in Africa.

2 Lo studio di Tonzar si rivela di grande interesse proprio perché interroga la produzione letteraria di questa fase storica. Attraverso l'analisi di quattro testi, il saggio scandaglia la "fisionomia dell'immaginario coloniale degli italiani, ovvero l'eredità storica e testuale" (p. 21) della retorica coloniale, dimostrando efficacemente che "i miti e gli stereotipi di lunga durata caratterizzanti la coscienza coloniale degli italiani" (p. 23) non cessano con la caduta dell'Impero. Anzi persistono e operano in maniera più e 
meno conscia nelle produzioni culturali italiane. Se la rimozione del colonialismo è stata favorita dalle "modalità esclusivamente militari di perdita delle colonie, che ebbero l'effetto di sottrarre l'Italia a un confronto con il nazionalismo africano" (p. 29), Tonzar sottolinea che la mancata elaborazione coincide inoltre con la necessità di costruire una nuova identità italiana, repubblicana, in rottura con la precedente ideologia fascista.

Dopo un'introduzione generale e un primo capitolo d'ordine storico, i quattro capitoli successivi contengono l'analisi di quattro autori e delle loro opere, secondo una scansione diacronica. Il primo è Paolo Cesarini, senese, soldato nella campagna d'Etiopia, di cui vengono analizzati Un uomo in mare (1937), testo che lascia trasparire "la sottile percezione di un divario tra le immagini della propaganda e la realtà" (p. 39), e la raccolta di racconti Mohamed divorzia (1944, ristampa 2005), che descrive un'Africa diversa da quella esaltata dalla propaganda, soprattutto per quanto riguarda la vita dei coloni. Il capitolo seguente propone una corposa analisi del romanzo di Ennio Flaiano Tempo di uccidere (1947), "contronarrazione non solo del roboante colonialismo fascista ma anche, e soprattutto, della retorica assolutoria postbellica" (p. 55). Il quarto capitolo si concentra su Mario Tobino, psichiatra di formazione, inviato in Libia durante la guerra, della cui opera Il libro della Libia (1945, riedita nel 1952 con il titolo Il deserto della Libia) viene proposta una ricostruzione filologica volta a seguire le posizioni dell'autore rispetto al colonialismo italiano. Secondo Tonzar, Tobino "non mette in discussione il colonialismo in toto, bensì le modalità della sua attuazione" (p. 109). Il saggio si chiude con l'analisi di Settimana nera del giornalista e scrittore Enrico Emanuelli, corrispondente in Africa per il quotidiano genovese Il Lavoro. Pubblicato nel 1961, Settimana nera, ambientato in Somalia all'epoca dell'AFIS, denuncia la persistenza di schemi e stereotipi risalenti al periodo fascista, suggerendo che "una vera decolonizzazione culturale nell'Italia repubblicana non è ancora avvenuta" (p. 133). Settimana nera è uno dei pochissimi testi ambientati durante l'AFIS e pubblicato a ridosso dell'AFIS stessa. L'ultimo capitolo si rivela dunque di grande importanza critica. Malgrado infatti il ritrovato interesse per l'esperienza coloniale italiana, il periodo dell'AFIS aspetta ancora di essere vagliato in profondità. 